\title{
Moisture variations during the first millennium CE and their linkage with social developments along the Silk Road in northwestern China
}

\section{Yong Zhang ( $\sim$ zhangyong@igsnrr.ac.cn )}

Institute of Geographic Sciences and Natural Resources Research Chinese Academy of Sciences https://orcid.org/0000-0001-5715-9301

\section{Xuemei Shao}

Institute of Geographic Sciences and Natural Resources Research Chinese Academy of Sciences

Qing Yang

Institute of Atmospheric Physics Chinese Academy of Sciences

\section{Zhi-Yong Yin}

University of San Diego

\section{Research Article}

Keywords: tree ring, sc-PDSI, Qilian Mountains, drought, decadal variations

Posted Date: June 22nd, 2021

DOl: https://doi.org/10.21203/rs.3.rs-411295/v1

License: (c) (i) This work is licensed under a Creative Commons Attribution 4.0 International License. Read Full License

Version of Record: A version of this preprint was published at Climatic Change on October 1st, 2021. See the published version at https://doi.org/10.1007/s10584-021-03225-7. 


\section{Abstract}

Moisture conditions, especially those that occur as multi-decadal anomalies, have profound impacts on society, especially in arid and semi-arid regions. However, the lack of high-resolution climatic data for the first millennium CE greatly limits our understanding how moisture variations have influenced history. Here, we present an 1882-year (134-2015 CE) tree-ring chronology developed from the Qilian juniper (Juniperus przewalskii Kom.) growing in the western Qilian Mountains, northwest China. The tree-ring index correlates significantly with the May-June self-calibrating Palmer Drought Severity Index (sc-PDSI) and could therefore be used to reconstruct May-June moisture variations since $241 \mathrm{CE}$. The reconstruction reflects moisture conditions at the annual to multi-decadal time scales over the past two millennia. During the period from the 3rd to 8th centuries, there were prominent interdecadal fluctuations, with the 3rd century and the late 5th century being the wettest and driest periods in the reconstruction, respectively. The transition from the wet 3rd century to the dry 5th century corresponded with key events in Chinese history, namely the demise of the Western Jin Dynasty and the chaotic Southern and Northern Dynasties, as well as the fall of the ancient Loulan Kingdom in eastern Xinjiang. Thus, our reconstruction provides new evidence for the close linkage between abnormal climate conditions and social changes in ancient times.

\section{Introduction}

Moisture conditions, especially multi-decadal anomalies, have significant impacts on human societies. For example, the persistent wet conditions that likely lead to the rise of 13th-century Mongol Empire (Pederson et al., 2014), the decade of droughts and its associated dust storms that caused one of the most severe environmental catastrophes in U.S. history, i.e., the "Dust Bowl" during the 1930s (Cook et al., 2007; Schubert et al., 2004), and the megadrought during the late Ming Dynasty in China (Zhang et al., 2008) all had profound impacts on the society (Zhang et al., 2005; Zhang et al., 2010). More detailed information on moisture variations at the multi-decadal time scale on the long-term context is very important for both projecting the moisture variation scenarios in the future and assessing the impacts of climatic change on economic and societal development (Meehl et al., 2009). Because widely available instrumental records are limited to the last century, it is necessary to use proxy records such as tree rings to study multi-decadal events over the centuries. Fortunately, tree rings can provide data with annual resolution, are widely distributed, and are relatively accessible. For this reason, they have been used to reconstruct interannual-decadal climate variations during the past 2000 years in many parts of the world (Esper et al., 2012; Jones and Mann, 2004; Mann and Jones, 2003). However, the availability of tree-ring based reconstructions decreases with lengthening timespan, so there is a lack of reliable reconstructions during the first millennium CE, especially prior to approximately 800 CE (Breitenmoser et al., 2012; Ljungqvist et al., 2016).

Actually, the period prior to $800 \mathrm{CE}$ is extremely important because of several known climate anomalies and their significant impacts on human history. For example, the Roman Warm Period (the 1 st century3rd century) and the relevant rising and demise of the western Roman Empire (265-316 CE), the Late 
Antique Little Ice Age (6th century-7th century) with the turmoil of the Migration Period in Europe (4th-6th) (Büntgen et al., 2016; Büntgen et al., 2011), as well as the cold periods during the Wei, Jin, and NorthSouth Dynasties (181-540 CE) in ancient China and the warm periods during the Sui and Tang Dynasties (541-810 CE) (Ge et al., 2013), accompanied by frequent dynasty successions with severe social/political upheavals in China (304-581CE), all happened in the first 8 centuries (Ebrey, 1996). Due to the scarcity and the uneven spatial distribution of 2000 year-long high-resolution climate reconstructions, our understanding of the characteristics of climate change and its relationship with social activities during this period is still lacking, especially in arid and semi-arid regions, which are particularly sensitive to climate change and the corresponding human activities (Huang et al., 2016; Reynolds et al., 2007).

The Qilian Mountains are located along the north-eastern margin of the Tibetan Plateau. This region is rich in forest resources and serves as a major water source for the Hexi Corridor in arid and semi-arid northwestern China (Fig. 1). At the same time, the Hexi Corridor, situated north of the Qilian Mountains, has been a natural passage from the Middle Kingdom to her north-western territories since the ancient times. It has been an important channel for economic and cultural exchanges between China and Central Asian and European countries. The characteristics and impacts of climate change in the Qilian Mountains throughout history are of increasing interest. Many dendroclimatological studies have been carried out in this region, including, for instance, reconstructions of temperature and precipitation over the past several hundred years (Gou et al., 2015a; Liu et al., 2010; Liu et al., 2013; Qin et al., 2015; Sun and Liu, 2012; Yang et al., 2012; Zhang et al., 2011a; Zhang et al., 2014; Zhang et al., 2011b), and several millennium-long reconstructions of droughts and floods mainly concentrated in the central Qilian Mountains (Sun and Liu, 2012; Yang et al., 2012; Zhang et al., 2011b). However, few tree-ring based researches paid close attention to moisture variations before the 8 th century thus far.

In this study, we use tree-ring samples collected from standing dead and healthy living Qilian junipers (Sabina przewalskii Kom.) from the Jiuquan area in the western Qilian Mountains located in an inland arid region (Fig. 1) to develop a new ring-width chronology. In this region, Tian et al. (2007) and Liang et al. (2009) reconstructed soil moisture and precipitation variations, respectively, but only for approximately 200 years long. Yang et al. (2011) extended the drought record to 620 years subsequently. In 2015, an 850-year reconstruction of May-July Palmer's Drought Severity Index (PDSI) was established for the western Jiuquan area and used to analyze severe multi-decadal drought events and the impact of solar activity during the Little Ice Age (Gou et al., 2015b). Recently, Yang et al. (2019) reported a 1556-year-long ring-width chronology for the Hexi Corridor and compared the hydroclimatic changes between the Hexi Corridor and Qaidam Basin on different time-scales. They looked in particular at the Medieval Climate Anomaly (MCA, 800-1200 CE) and the drying trend during the 20th century. Here our new ring-width chronology is extended to $134 \mathrm{CE}$. Furthermore, we analyze multi-decadal variations in moisture conditions during the past 1775 years and their possible linkages with societal activities in and around the Qilian Mountains, with a focus in particular on the period from the 3rd century to the 8th century.

\section{Data And Methods}


The Jiuquan area is located in the western Hexi Corridor, north of the western Qilian Mountains (Fig. 1). It has a typical continental arid climate with an annual mean temperature of $7.5^{\circ} \mathrm{C}$ and annual total precipitation of $87.2 \mathrm{~mm}$ according to the data recorded at the Jiuquan meteorological station over the 1951-2015 period (data available from http://data.cma.cn). The highest temperature and most precipitation both occur in July. Qilian junipers grow sparsely on sunny and semi-sunny slopes at elevations of 3100-3700 meters above sea level (m a.s.I.) (Liu et al., 2006). Years of investigation in this region have revealed that Qilian junipers in this area are seldomly older than approx. 300 years. However, a few small patches of old-growth stands exist in some of the high and most inaccessible reaches of the mountains, where they have survived for more than 500 years. Some dead trees that are much older than the living trees can also be found in these areas.

The tree-ring samples were obtained from the Yaoquan Valley (E97.88, N39.61), 50 kilometers west of the Jiuquan City, Gansu Province, China. The Yaoquan Valley runs from north to south, and the tree ring samples were taken from four sites located on the south-facing sunny slopes on both side of the valley, with the distances between the sites less than 10 kilometers. The sampling elevations ranged from 3100 to $3500 \mathrm{~m}$ a.s.l., and the dead trees were distributed at various altitudes, but mainly at somewhat higher altitudes (approx. 3250-3450 $\mathrm{m}$ a.s.I.). For these dead trees, there were no signs of insect damage on the bark side, but fire scars could be seen on the exposed roots of a few trees. Two or more increment cores were extracted from each living tree and standing dead snag. In total, 278 cores from 129 trees were collected, including 82 dead trees (171 cores). The sampling was conducted during 2016.

Monthly temperature and precipitation data were obtained for the Jiuquan Station (1951-2015) from the China Meteorological Administration. The monthly self-calibrating Palmer's Drought Severity Index (scPDSI) at four grid points (N39.25, E97.75 / N39.75, E97.75 / N39.25, E98.25 / N39.75, E98.25) around the YQ sampling area (1952-2015) were downloaded from the website of the Climatic Research Unit (https://crudata.uea.ac.uk/cru/data/drought/) (Osborn et al., 2017; van der Schrier et al., 2013). The arithmetic means of the monthly sc-PDSI values in different monthly/seasonal combinations were calculated for further analysis.

\section{Methods:}

\section{a. Chronology development}

All of the sample cores were prepared in the laboratory using standard dendrochronological techniques (Stokes and Smiley, 1996). We cross-dated the rings visually (Fritts, 1976; Stokes and Smiley, 1996) and measured the ring widths to the nearest $0.01 \mathrm{~mm}$ using a Lintab 5 measuring system. We then statistically verified the cross-dating accuracy using the COFECHA program (Holmes, 1983). Because the four sampling sites were very close with similar environments, tree growth at these sites should be governed by the same climatic conditions. Therefore, all ring-width series cross-dated well between the sites, with the average segment correlation coefficients of individual series with the master series ranging 
from 0.57 to 0.83 . The mean of correlation coefficients between each series and the master series was 0.77 . For this reason, all of the raw measurements were combined into a single chronology (hereafter referred to as YQ; Fig. 2). Because the mean segment length of all measurements is 282 years with the longest measurement of 1481 years, we could not obtain a reliable regional tree growth curve for the Regional Curve Standardization (RCS) detrending technique, which is an effective method of retaining low-frequency variations (Briffa and Melvin, 2008; Melvin and Briffa, 2008). The ring-width series were detrended using the Signal-Free (SF) procedure, which can reduce or remove the distortion introduced during the traditional standardization process (Melvin and Briffa, 2008). In this procedure, individual series were detrended using cubic smoothing splines with a $50 \%$ frequency response cut-off at approximately $67 \%$ of the series length for the original chronology [Melvin and Briffa (2008). To account for changes in the variance associated with changes in sample depth through time, the variance in the chronology was stabilized using a method introduced by Osborn et al. (1997). The stabilized signal-free chronology was then used in the subsequent reconstruction. We used the RCSigFree program (Cook et al. 2014; https://www.Ideo.columbia.edu/tree-ring-laboratory/resources/software) to develop the SF chronology. Then we used the ARSTAN program with the same spline function to fit the growth trend (Cook, 1985) and obtained the basic statistical information for the common period 1230-1440 CE, including average sensitivity, signal-to-noise ratio, inter-series correlation (Rbar), and expressed population signal (EPS). The length of the reliable chronology is determined using the EPS statistic: an EPS greater than 0.85 is generally considered to be an acceptable threshold for a reliable chronology for climatic reconstruction (Cook and Kairiukstis, 1990).

\section{b. Climate-growth relationship and reconstruction}

Correlation analysis between the original and first differenced YQ chronology and climate variables from previous September to the current September during 1951-2015CE was used to investigate the climatic information contained in the YQ chronology and to determine the main factors limiting tree growth at the study site (Blasing et al., 1984; Fritts et al., 1971). Regression analysis was used to establish the transfer function of reconstruction using the data for the full calibration period. Both the leave-one-out correlation and the split-period verification methods were applied to examine the robustness of the reconstruction model (Meko and Graybill, 1995). The statistics of the calibration and verification include the sign test (ST), the first difference sign test (FST), the product-mean T test (PMT), reduction of error (RE), and coefficient of efficiency (CE) (Fritts, 1976). RE and CE values above zero indicate that the model has robust estimation skill (Cook et al., 1999).

To assess the regional significance of the reconstruction, the CRU gridded precipitation data (TS 4.01) (Mitchell and Jones, 2005) and CRU self-calibrating PDSI data (1951-2015, 0.5 $\left.\times 0.5^{\circ}\right)$ were correlated with the actual and reconstructed series, respectively, using the KNMI Climate Explorer (http://climexp.knmi.nl). We also correlated the reconstruction series with the gridded June-August PDSI reconstruction from the Monsoon Asia Drought Atlas (MADA) (Cook et al., 2010) for the longer time scale during 1300-2005 CE. Due to the lack of long chronologies in the Xinjiang area and eastern China, the interval of correlation analysis was set from 1700 CE to 2005 CE. 


\section{Results}

1. Characteristics of the $Y Q$ chronology

Table 1 shows the statistics of the YQ standard chronology. The YQ chronology exhibits a relatively high mean sensitivity value (0.385) and a low first-order autocorrelation (0.195), indicating its potential for reflecting past interannual environmental changes, most likely moisture variations. Values for the average correlation among series, the signal-to-noise ratio $(\mathrm{S} / \mathrm{N})$, the explained variance by the first principal component, and the representativeness of the sample population are relatively high, indicating that variation in ring widths across the sampling sites is consistent. The total length of the chronology is 1882 years (134-2015 CE); the starting year of the robust chronology (when EPS reached 0.85) is $241 \mathrm{CE}$ (Fig. 2).

\section{Correlation analysis}

As shown in Fig. 3a, the correlations between the tree-ring index and precipitation in the early growing season (May and June) are statistically significant and positive. At the same time, its correlations with temperature in March, May and June are negative (statistically significant in March and June). Correlations between the tree-ring index and the monthly sc-PDSI are consistently positive and statistically significant from September of the previous year to August of the current year. The results of the first order differenced data are similar to those of the original data (Fig. 3b), but the correlation coefficients are slightly higher. For instance, correlations with March temperature and precipitation in May and June remained statistically significant. The same is true for the positive correlations with May and June Sc-PDSI. Further analysis of various monthly/seasonal combinations revealed that the highest correlation $(0.68 ; p<0.001)$ occurred between the tree-ring index and the average May-June sc-PDSI at the four grid points. For this reason, May-June sc-PDSI was identified as the target of the reconstruction.

\section{Calibration and verification}

The scatter plot shows that the tree-ring index has a non-linear relationship with the May-June sc-PDSI (Fig. 4a). This means that while dry years (less precipitation) would in general cause narrow ring widths, wet years, on the other hand, would produce rings with a reduced range of variation for the same increment of the sc-PDSI values, from medium to wide ring widths. In fact, there seemed to be a power relationship between the tree-ring index and May-June sc-PDSI. Accordingly, the tree-ring index and scPDSI were further logarithmically transformed (a base-10 logarithm with a constant of 5 being added to the sc-PDSI to make all values positive) (Feng et al., 2013). The resulting scatter plot shows a more linear relationship with a correlation coefficient of 0.71 (Fig. 4b). Therefore, the transfer function was estimated by linear regression using the logarithmically transformed data:

\section{$\log _{10}(5+S C-P D S I)=0.71+0.71 \log _{10}(S S F),(1)$}


where sc-PDSI is the average May-June sc-PDSI at the four grid points closest to the sampling area, and SSF is the ring-width index of the YQ stabilized signal-free chronology. The final reconstruction transfer function is:

\section{Sc-PDSI = (10SSF) ${ }^{0.71}-\mathbf{5} .(2)$}

The model explains $50.5 \%$ of the variance in the May-June sc-PDSI for the entire calibration period. The results of the split-period verification and leave-one-out analyses indicate good model prediction skills, as represented by positive RE and CE statistics in all cases (Table 2). The overall ST, FST, and PMT results passed the 0.95 confidence level, except for the ST results for the verification periods of 1952-1983 and 1984-2015. As shown in Fig. 4c, the reconstructed values match the observed sc-PDSI values very well in dry years, except for 1957 and 1986. The variations in the observed values were larger than those in the reconstructed values, especially in some wetter years. This suggests that the model performs not as well in extremely wet years. However, the evaluation statistics in Table 2 and the general agreement between the actual and reconstructed values indicate that the regression model performance is stable and reliable. Thus, the model can be used to reconstruct interannual to multi-decadal drought variability in the western Qilian Mountains since $241 \mathrm{CE}$.

\section{Interannual and interdecadal moisture variation patterns}

The reconstructed May-June Sc-PDSI series revealed prominent interannual and interdecadal moisture variations over the past 1775 years (Fig. 4d), with sc-PDSI values ranging from -4.6 to 3.4. Based on the 11 -year running means and the \pm 1.0 standard deviation of the reconstructed series, 19 distinct pluvial and 15 dry periods were identified (Fig.4d). During the past 1775 years, the driest and wettest periods were the late $5^{\text {th }}$ century and the middle-late $3^{\text {rd }}$ century, respectively. For the period spanning the middle of the $3^{\text {rd }}$ century to the end of the $8^{\text {th }}$ century, decadal moisture variation is characterized by large fluctuations. In particular, the $3^{\text {rd }}$ century was significantly wetter than normal but quickly became drier. By the end of the $5^{\text {th }}$ century, the moisture condition has declined to its lowest point on record. Although it became wetter again in the $6^{\text {th }}$ century, the period from the $4^{\text {th }}$ to the $8^{\text {th }}$ century was generally dry.

To evaluate the spatial representativeness of our reconstruction, we correlated the observed and reconstructed May-June sc-PDSI with the CRU gridded sc-PDSI field during 1952-2015 (Fig. 5). The results of the correlation analysis show that the actual Sc-PDSI is significantly correlated with observed moisture variation in the surrounding area with a spatial extent approx. from $35-42^{\circ} \mathrm{N}$ and $75-102^{\circ} \mathrm{E}$ (Fig. 5a). The spatial pattern of the correlation coefficients between the reconstructed May-June sc-PDSI and observed moisture variation in the surrounding area (Fig. 5b) is very similar to that of the actual sc-PDSI (Fig. 5a). The regions with significant correlations are mainly distributed in the Qilian Mountains and the area to the west, i.e., the northern part of the Tibetan Plateau (Fig. 5b). These spatial patterns remain essentially unchanged after detrending the data (Fig. 5c), suggesting robust relationships in both interannual and interdecadal time scales. The correlation results of our reconstruction with the PDSI series from the 
MADA data (Cook et al. 2010) reveals a belt of significant correlations running NW-SE from the northeastern Tibetan Plateau (including the Qilian Mountains) to central China (Fig. 5d).

\section{Discussion}

\section{Climatic implications of the YQ chronology and validity of regression model}

Moisture is a common limiting factor for tree growth in arid and semi-arid regions (Fritts, 1976). Our sampling sites are located in an arid area that receives less than $100 \mathrm{~mm}$ of precipitation annually, as indicated by the records from the nearby Jiuquan weather station, although the mountain slopes with the Qilian juniper stands receive more precipitation (Shao et al., 2005). The radial growth of Qilian junipers is mostly dependent on soil moisture recharged from precipitation and thus responds positively to precipitation and sc-PDSI variability (Gou et al., 2015b). As shown in Fig. 3, the positive (negative) correlations with precipitation (temperature, especially maximum temperature) in the early growing season indicate the typical moisture stress on Qilian Juniper growth (Shao et al., 2010; Yang et al., 2019; Yin et al., 2008). Such relationships are widely reported for other studies in the Qilian Mountains and surrounding areas (Gou et al., 2015a; Gou et al., 2015b; Yang et al., 2014; Zhang et al., 2015b; Zhang et al., 2013). The significant positive correlations between the tree-ring index and precipitation and sc-PDSI in May and June indicated moisture conditions in the current early growing season have impacts on the ring width. A related study showed that moisture availability from May to June affects the radial growth rate and this period accounts for more than $60 \%$ of the total annual growth (Zhang et al., 2016). Therefore, moisture availability in May and June could significantly influence the whole ring width of any given year. In addition, the results of the correlation analysis with the gridded sc-PDSI field (Fig. 5) confirm the good representation of drought variations along the northern margin of the Tibetan Plateau. This is especially true for the north-eastern part of Tibetan Plateau, which further validates our decision to use May-June sc-PDSI as the reconstruction target.

It should be mentioned that our chronology is combined with both living trees and dead snags. Previous study has found that the Qilian junipers growing below the upper $20 \%$ of the forest belt on the northeastern Tibetan Plateau were precipitation-sensitive (Zhang et al., 2015a). In this site, Qilian junipers can still be found above 3650 meters, while all our samples were taken below $3500 \mathrm{~m}$ a.s.l. and are moisture-sensitive as we described above. At the same time, there was a significant correlation between the dead and living tree cores in the overlapped periods, with most of the correlation coefficients higher than 0.7 , indicating that their responses to climatic factors were very similar. In addition, many of the dead trees probably died hundreds of years ago, among them, 12 trees died before one thousand years ago. During the sampling process, we observed that the barks of the dead trees have decayed and lost, so did the wood immediately beneath the bark, now exposed to weathering. In fact, it was very difficult to retrieve a complete core by retaining the most outer portion of the sample. As a result, we speculate that the rings representing the years when the trees were weakened before their eventual death were lost by decay or in the sampling process. On the other hand, the dead tree cores used in chronology construction all showed good growth conditions for the interior portions. Therefore, the impacts of the abnormal 
factors leading to the death of these trees have most likely been eliminated and not reflected in the final chronology.

The ST results did not pass the 0.95 confidence level for the verification periods of 1952-1983 and 19842015(Table 2), which can be partly explain by the disagreements between the observed and predicted values in pluvial years (Fig. 4c). In dry regions, narrower rings provide more precise climatic information than do wider rings (Fritts, 1976). In pluvial years, precipitation becomes abundant, and the additional water is unavailable to the tree due to run off or percolation below the root zone, and therefore of no benefit to growth (Fritts, 1976; Sun et al., 2017). Accordingly, the sensitivity of Qilian juniper ring-width increment to available precipitation decreases. Furthermore, because the sc-PDSI calculation considers the cumulative effect of water deficits in the previous 9-12 months (Wells and Goddard, 2004), the observed sc-PDSI values probably do not reflect the true moisture conditions in some years, such as the dry years of 1957 and 1986, this may be another reason. In addition, the disagreement between the observed and predicted values mostly occurred after 2001, which has also been found in other sites (Fang et al., 2012; Gou et al., 2015b; Yang et al., 2019). Since automatic weather station system in China was completed around 2003 (Li et al., 2013), the difference between manual observation and automatic observation may contribute to such disagreement.

\section{Comparisons with regional hydroclimate reconstructions}

As shown in Fig. 5d, significant correlations between our reconstruction and the PDSI series from the MADA data (Cook et al. 2010) were found in the north-eastern Tibetan Plateau and its surroundings, which also extended toward southeast (Fig. 5d). We further compared our reconstruction to several reconstructions of moisture conditions in the vicinity, including the ratios of Artemisia and Amaranthaceae (A/C) in the Tian'E Lake (Zhang et al., 2018) (Fig. 6a) and two tree-ring-based moisture reconstructions (JQ and QF) (Gou et al., 2015b; Yang et al., 2019) (Fig. 6b) located in the Jiuquan area. Compared with the series of Tian'E Lake, it is found that the wet and dry periods corresponded well, including certain dry periods in the mid-19th century, the mid-late 17th century, the middle and late 15th century, and the mid-late 13th century, and several wet periods in the 1220s, 1610s, 18th, and late 19th century. However, there are also differences between the two series, especially before $1200 \mathrm{CE}$. For instance, there was an abnormal wet period in Tian'E Lake near the 720s while the YQ series showed a relatively dry period. The altitude of the Tian'E Lake is $3012 \mathrm{~m}$ a.s.I., which is lower than that of our site, therefore, such disagreement may be explained by the differences in climatic implications and altitude, a difference of precipitation between mountain and lowland was can be found in eastern Qaidam Basin of the Tibetan Plateau (Dong et al., 2021). Both the JQ and QF series are in good agreement with our reconstruction on interannual-interdecadal timescales, with correlation coefficients of 0.86 (JQ, 1161$2010 \mathrm{CE}$ ) and 0.54 (QF, 455-2011CE), respectively. Additionally, 24 out of 46 drought events recorded by historical documents from Jiuquan and Dunhuang (Dunhuang City Annals Compilation Committee, 1994; Jiuquan history office, 1998) corresponded with the dry years in our reconstruction during the period of 241-1960CE. Among them, 6 out of 9 late spring-early summer droughts (4 out of 7 summer droughts, 2 
out of 4 autumn droughts) corresponded to the dry years in our reconstruction, suggesting that our reconstruction can capture the spring drought events better.

To test the strength of spatial representation of our reconstruction, we further compared it with several tree-ring-based reconstructions farther from our study area, including an annual previous August-current July precipitation reconstruction for the Zhangye area (HYG) (Zhang et al., 2011b), a January-June moisture balance reconstruction for the eastern Qaidam Basin (Yin et al., 2016b) , and an annual (previous July-current June) precipitation reconstruction for the north-eastern Tibetan Plateau (Yang et al., 2014). In addition, the May-September historical document-based dry-wet index series for northern China (Zheng et al., 2006) and in the stalagmite oxygen stable isotope record from the Huangye Cave in central China (Tan et al., 2010) were also included (figure 6h and 6i). The correlation coefficients between the YQ series and the three tree-ring-based reconstructions listed above are $0.55,0.39$, and 0.40 , respectively, all statistically significant at the 0.01 level. The dry and wet fluctuations in our reconstruction on the decadal scale were consistent with those of tree-ring-based reconstructions. Most of the multidecadal drought and pluvial events recorded in our reconstruction can be found in three tree ring-based reconstructions. In addition, some of these events, such as the droughts in the 460s-500s and $1450 \mathrm{~s}-$ 1510 s and the pluvial events in the 790s-820s and 1860s-1910s, are also found in the North China historical document and Central China stalagmite series. Overall, the major wet and dry events shown by our reconstruction are also found in other reconstructions presented in Figure 6, suggesting that our reconstruction captures signals of regional inter-annual to decadal moisture variability over the northeastern Tibetan Plateau and beyond.

3. The link between interdecadal moisture variations and human activities during the 3rd through the 8th centuries

Extended periods of wet or dry conditions in arid regions often have great impacts on human society, especially in ancient times. For instance, Zhang et al. (2018) found that persistent droughts were responsible for the abandonment of several settlements and cities in the Qilian Mountains/Hexi Corridor region, including the ancient city of Dunhuang. As mentioned above, the tree-ring-based reconstructions in northeastern TP show a good agreement among themselves, while some disagreements can be found between our reconstruction in high mountainous area and the lake sediment-based reconstruction in lowland. However, a latest research indicated that precipitation in the surrounding mountains instead of the lowland itself facilitated the prosperity of ancient civilization in a mountain-basin system (Dong et al., 2021). High precipitation from high mountains provided abundant runoff to nourish the oasis in the lowland, and facilitated agro-pastoral production and human settlement, which was more conducive to social stability and economic development. Therefore, we can further investigate the possible linkage between regional hydroclimate and social activities based on our reconstruction and the surrounding climate reconstructions.

As shown in Fig. 6, the period from 240 to 310 CE was one of the most significant wet periods of the past 1775 years. Historical archives and the stalagmite record (Fig. $6 \mathrm{~g}$ and $6 \mathrm{~h}$ ) indicated that the climate 
during this period was wet throughout northern and central China. This period corresponded to the Western Jin Dynasty (266-316 CE), the dynasty that unified the warring states of the Three Kingdoms period and controlled our study area at the time (Ebrey, 1996). The climate then rapidly became drier starting around $310 \mathrm{CE}$, which was when the Western Jin Dynasty collapsed and nomads from the north and northwestern parts of China invaded central China (Fig. 7a). Although the civil unrest of ethnic minorities at the time was related to the emergence of a minority population in northern inland China and the escalation of national oppression (Cui, 2012; Ebrey, 1996; Yoshiaki, 2019), the dry conditions during this time would have inevitably lead to the degradation of pastures in northern and northwestern China, and hence to the increased livestock mortality (Begzsuren et al., 2004; Sternberg, 2008). When drought occurred, nomads were pushed to migrate southward and invade agriculturalist polities (Pei et al., 2019). In doing so, they invaded agricultural settlements of the Han Chinese, as this was the only way to survive a deteriorating climate (Pei et al., 2019; Pei and Zhang, 2014).

The increasing dryness in this region eventually peaked around the end of the $5^{\text {th }}$ century. Nomadic groups conquered and occupied the northern part of central China during this period (Su et al., 2016), while frequent regime changes occurred in our study area (Ebrey, 1996; Yoshiaki, 2019). When moisture conditions improved in the latter half of the 6th century, the region that included our study area was governed successively by two unified dynasties, the Sui Dynasty (581-617 CE) and the Tang Dynasty (618-907 CE) (Twitchett and Fairbank, 1979). Similarly, the ancient Silk Road region entered a period of prosperity around the year 609 CE (Jiuquan-history-office, 1998). In fact, moisture conditions in and around our study region were either normal or wetter than normal during two other Silk Road boom periods, the 240s-250s and the 710s-750s CE (Dunhuang City Annals Compilation Committee, 1994; Gao, 2011) (Fig. 6d).

As shown in Figure 7, the high frequency periods of war initiation between nomadic and farming groups often corresponded the dry periods during the period from the $3^{\text {rd }}$ century to the $8^{\text {th }}$ century. However, we would add that the lack of warfare in northwestern China around the late $5^{\text {th }}$ century, a period of notable dryness, was largely the result of a southward shift of the warring zones associated with the invasion of the nomads, and the frequent wars during the Sui Dynasty were mainly related to the social unrest before and after dynastic change. The reduction of living resources caused by climate deterioration was more likely to lead to conflicts between nomadic and farming groups. In the 10-30 yr scales, precipitation displayed more significant effects on the social vicissitudes (Yin et al., 2016a). For example, in the late 3rd century, persistent drought occurred in Northwest China (He et al., 2013; Liu et al., 2009; Wang et al., 2019; Yang et al., 2014; Yin et al., 2016b) , more than 100000 people in Gansu Province migrated to Sichuan Province due to years of famine, which led to the outbreak of war and the subsequent establishment of the Cheng Han regime(Compile Group of Chinese Military History, 2002). Too little precipitation can trigger pasture deterioration and nomadic migrations, especially for people in northern and north-western China (Pei and Zhang, 2014). It should be emphasized that many factors played a role in determining the political and economic conditions that led to instances of warfare between the nomads and the agricultural Han Chinese dynasties. However, our results indicate that unusual moisture 
variations seemed to have played indirect but important roles in influencing human activities during ancient times.

\section{Conclusion}

In this paper, we present a 1775-year May-June sc-PDSI reconstruction for the western Qilian Mountains based on a new tree-ring width chronology developed from Qilian juniper by combining 278 sample cores from healthy living trees and 171 cores from dead snags. This study provides new climate information for the period prior to $800 \mathrm{CE}$, a period for which high-resolution climate data is especially scarce. The reconstruction reveals several distinct wet and dry periods during the past 1775 years, including an especially wet period during the 3rd century (241-259 CE /286-311 CE) and an especially dry period in the late 5th century (457-497 CE). It also provides independent information that significant events in human history were likely related to climate change and variation on the interannual to interdecadal timescales. Future work is needed to provide more evidences about the impacts of interdecadal droughts on human history.

\section{Declarations}

\section{Acknowledgements:}

This work was supported by the National Key R\&D Program of China [Grant No. 2016YFA0600401], the National Natural Science Foundation of China [Grant No. 41630529 and 41471170] and University of San Diego (FRG\# 2017-18). We sincerely thank Prof. Bao Yang, Prof. Xiaohua Gou, Prof. Yun Su and Dr. Hongli Wang for providing the additional data used in this study and for valuable discussions and kind assistance.

\section{References}

Büntgen U, S.Myglan V, Ljungqvist FC, McCormick M, Cosmo ND, Sigl M, Jungclaus J, SebastianWagner, Krusic PJ, Esper J, Kaplan JO, Vaan MACd, Luterbacher J, LukasWacker17 WT, Kirdyanov AV (2016) Cooling and societal change during the Late Antique Little Ice Age from 536 to around 660 AD. Nat Geosci 9:231-237.

Büntgen U, Tegel W, Nicolussi K, McCormick M, Frank D, Trouet V, Kaplan JO, Herzig F, Heussner K-U, Wanner H, Luterbacher J, Esper J (2011) 2500 Years of European Climate Variability and Human Susceptibility. Science 331:578-582.

Begzsuren S, Ellis JE, Ojima DS, Coughenour MB, Chuluun T (2004) Livestock responses to droughts and severe winter weather in the Gobi Three Beauty National Park, Mongolia. J Arid Environ 59:785-796.

Blasing TJ, Solomon AM, Duvick DN (1984) Response functions revisited. Tree-Ring Bull. 44:1-15. 
Breitenmoser P, Beer J, Brönnimann S, Frank D, Steinhilber F, Wanner H (2012) Solar and volcanic fingerprints in tree-ring chronologies over the past 2000 years. Palaeogeogr Palaeoclimatol Palaeoecol 313-314:127-139.

Briffa KR, Melvin TM (2008) A Closer Look at Regional Curve Standardization of Tree-Ring Records: Justification of the Need, a Warning of Some Pitfalls, and Suggested Improvements in Its Application.

Compile Group of Chinese Military History (2002) Chronology of Warfare in Ancient China. The People's Liberation Army Press of China, Beijing.

Cook ER (1985) A time-series analysis approach to tree-ring standardization. PhD dissertation, The University of Arizona press, Tucson.

Cook ER, Anchukaitis KJ, Buckley BM, D'Arrigo RD, Jacoby GC, Wright WE (2010) Asian monsoon failure and megadrought during the last millennium. Science 328:486-489.

Cook ER, Kairiukstis LA (1990) Methods of dendrochronology: Applications in the environmental sciences. Kluwer Academic Publishers, Dorefrecht.

Cook ER, Meko DM, Stahle DW, Cleaveland MK (1999) Drought reconstructions for the continental United States. J Clim 12:1145-1162.

Cook ER, Seager R, Cane MA, Stahle DW (2007) North American drought: Reconstructions, causes, and consequences. Earth-Sci Rev 81:93-134.

Cui Y (2012) Research on the political pattern of the North during the period of the Sixteen Kingdoms. Doctor thesis, Nankai University, Tianjin City.

Dong G, Li T, Zhang S, Ren L, Li R, Li G, Xiao Y, Wang Z, Chen F (2021) Precipitation in surrounding mountains instead of lowlands facilitated the prosperity of ancient civilizations in the eastern Qaidam Basin of the Tibetan Plateau. Catena 203:105308.

Dunhuang City Annals Compilation Committee (1994) Dunhuang City Annals. Xinhua Publishing House, Beijing.

Ebrey PB (1996) The Cambride illustrated history of China. Cambridge University Press, London.

Esper J, Frank DC, Timonen M, Zorita E, S.Wilson RJ, Luterbacher J, Holzkämper S, Fischer N, SebastianWagner, Nievergelt D, Verstege A, Büntgen U (2012) Orbital forcing of tree-ring data. Nat Clim Change 2:862-866.

Fang K, Gou X, Chen F, Liu C, Davi N, Li J, Zhao Z, Li Y (2012) Tree-ring based reconstruction of drought variability (1615-2009) in the Kongtong Mountain area, northern China. Global Planet Change 80-81:190197. 
Feng C, Wang H, Lu N, Tu XM (2013) Log transformation: application and interpretation in biomedical research. Statiistics in medicine 32:230-239.

Fritts HC (1976) Tree Rings and Climate. Academic Press, London.

Fritts HC, Blasing TJ, Hayden BP, Kutzbach JE (1971) Multivariate Techniques for Specifying Tree-Growth and Climate Relationships and for Reconstructing Anomalies in Paleoclimate. J Appl Meteorol Clim 10:845-864.

Gao R (2011) The general history of Hexi Corridor. Tianjin Classics Publishing House, Tianjin.

Ge QS, Zheng JY, Hao ZX, Liu HL (2013) General characteristics of climate changes during the past 2000 years in China. Sci. China Earth Sci 56:321-329.

Gou X, Deng Y, Gao L, Chen F, Cook E, Yang M, Zhang F (2015a) Millennium tree-ring reconstruction of drought variability in the eastern Qilian Mountains, northwest China. Clim Dynam 45:1761-1770.

Gou X, Gao L, Deng Y, Chen F, Yang M, Still C (2015b) An 850-year tree-ring-based reconstruction of drought history in the western Qilian Mountains of northwestern China. Int J Climatol 35:3308-3319.

He Y, Zhao C, Wang Z, Wang H, Song M, Liu W, Liu Z (2013) Late Holocene coupled moisture and temperature changes on the northern Tibetan Plateau. Quaternary Sci Rev 80:47-57.

Holmes RL (1983) Computer-assisted quality control in tree-ring dating and measurement. Tree-Ring Bull 43:69-95.

Huang J, Yu H, Guan X, Wang G, Guo R (2016) Accelerated dryland expansion under climate change. Nat Clim Change 6:166-171.

Jiuquan history office (1998) Jiuquan city annals. Lanzhou universtioy press, Lanzhou.

Jones PD, Mann ME (2004) Climate over past millennia. Rev Geophys 42:RG2002.

Li Y, Li F, Zhao Z, Guo H, Sun L, Li Z, Zhou Q, Zhen W (2013) Construction of operation monitoring system fo mesoscale automatic weather stations in China (in Chinese). Meteorological Science and Technology 41:231-235.

Liang E, Shao X, Liu X (2009) Annual precipitation variation inferred from tree rings since A.D. 1770 for the western Qilian Mts., Northern Tibetan Plateau. Tree-Ring Res 65:95-103.

Liu X, Dong H, Yang X, Herzschunh U, Zhang E, Stuut J-BW, Wang Y (2009) Late Holocene forcing of the Asian winter and summer monsoon as evidenced by proxy records from the northern Qinghai-Tibetan Plateau. Earth Planet Sc Lett 280:276-284.

Liu X, Wang Q, Meng H (2006) Qilian Juniper. China Science and Technology Press, Beijing. 
Liu Y, Sun J, Song H, Cai Q, Bao G, Li X (2010) Tree-ring hydrologic reconstructions for the Heihe River watershed, western China since AD 1430. Water Res 44:2781-2792.

Liu Y, Wang Y, Li Q, Sun J, Song H, Cai Q, Zhang Y, Yuan Z, Wang Z (2013) Reconstructed May-July mean maximum temperature since 1745 AD based on tree-ring width of Pinus tabulaeformis in Qianshan Mountain, China. Palaeogeogr Palaeoclimatol Palaeoecol 388:145-152.

Ljungqvist FC, Krusic PJ, Sundqvist HS, Zorita E, Brattström G, Frank D (2016) Northern Hemisphere hydroclimate variability over the past twelve centuries. Nature 532:94-98.

Mann ME, Jones PD (2003) Global surface temperatures over the past two millennia. Geophys Res Lett. 30.

Meehl GA, Goddard L, Murphy J, Boer G, Danabasoglu G, Dixon KW, Giorgetta M, Greene AM, Hawkins E, Hegerl GC, Karoly DJ, Kimoto M (2009) Decadal prediction: Can it be skillful? Bull Amer Meteorol Soc 90:1467-1485.

Meko D, Graybill DA (1995) Tree-Ring Reconstruction of Upper Gila River Discharge. Water Resour Bull 31:605-616.

Melvin TM, Briffa KR (2008) A "signal-free" approach to dendroclimatic standardisation. Dendrochronologia 26:71-86.

Mitchell TD, Jones PD (2005) An improved method of constructing a database of monthly climate observations and associated high-resolution grids. Int J Climatol 25:693-712.

Osborn T, Barichivich J, Harris I, van der Schrier G, Jones P (2017) Monitoring global drought using the self-calibrating Palmer Drought Severity Index [in "State of the Climate in 2016"]. Bull Amer Meteorol Soc 98:s32-s33.

Osborn T, Briffa K, Jones P (1997) Adjusting variance for samplesize in tree-ring chronologies and other regional mean timeseries. Dendrochronologia 15:89-99.

Pederson N, Hessl AE, Baatarbileg N, Anchukaitis KJ, Cosmo ND (2014) Pluvials, drought, the Mongol Empire, and modern Mongolia. P Natl Acad Sci USA 111:4375-4379.

Pei Q, Lee HF, Zhang DD, Fei J (2019) Climate change, state capacity and nomad-agriculturalist conflicts in Chinese history. Quatern Int 508: 36-42.

Pei Q, Zhang DD (2014) Long-term relationship between climate change and nomadic migration in historical China. Ecol Soc 19:68.

Qin C, Yang B, Bräuning A, Grießinger J, Wernicke J (2015) Drought signals in tree-ring stable oxygen isotope series of Qilian juniper from the arid northeastern Tibetan Plateau. Global Planet Change 125:48- 
59.

Reynolds JF, Smith DMS, Lambin EF, II BLT, Michael Mortimore, Batterbury SPJ, Downing TE, Dowlatabadi H, Fernández RJ, Herrick JE, Huber-Sannwald E, Jiang H, Leemans R, Lynam T, Maestre FT, Ayarza M, Walker B (2007) Global desertification: Building a science for dryland development. Science 316:847-851.

Schubert SD, Suarez MJ, Pegion PJ, Koster RD, Bacmeister JT (2004) On the Cause of the 1930s Dust Bowl. Science 303:1855-1859.

Shao X, Huang L, Liu H, Liang E, Fang X, Wang L (2005) Reconstruction of precipitation variation from tree rings in recent 1000 years in Delingha, Qinghai. Sci. China Earth Sci 48:939-949.

Shao X, Xu Y, Yin Z-Y, Zhu H, Wang S (2010) Climatic implications of a 3585-year tree-ring width chronology from the northeastern Qinghai-Tibetan Plateau. Quaternary Sci Rev 29:2111-2122.

Sternberg T (2008) Environmental challenges in Mongolia's dryland pastoral landscape. J Arid Environ 72:1294-1304.

Stokes MA, Smiley TL (1996) An introduction to tree ring dating. The University of Arizona Press, Tucson.

Su Y, Liu L, Fang X, Ma YN (2016) The relationship between climate change and wars waged between nomadic and farming groups from the Western Han Dynasty to the Tang Dynasty period. Clim Past 12:114.

Sun J, Liu Y (2012) Tree ring based precipitation reconstruction in the south slope of the middle Qilian Mountains northeastern Tibetan Plateau, over the last millennium. J. Geophys Res 117:D08108.

Sun Y, Bekker MF, DeRose RJ, Kjelgren R, Wang S-YS (2017) Statistical treatment for the wet bias in treering chronologies: a case study from the Interior West, USA. Environ. Ecol Stat 24:131-150.

Tan L, Cai Y, An Z, Edwards RL, Cheng H, Shen C-C, Zhang H (2010) Centennial- to decadal-scale monsoon precipitation variability in the semi-humid region, northern China during the last 1860 years: Records from stalagmites in Huangye Cave. Holocene 21:287-296.

Tian Q, Gou X, Zhang Y, Peng J, Wang J, Chen T (2007) Tree-ring based drought reconstruction (A.D. 1855-2001) for the Qilian Mountains, Northwestern China. Tree-Ring Res 63:27-36.

Twitchett D, Fairbank JK (1979) The Cambridge history of China. Cambridge University Press, New York. van der Schrier G, Barichivich J, Briffa KR, Jones PD (2013) A scPDSI-based global data set of dry and wet spells for 1901-2009. J Geophys Res-Atmos 118:4025-4048.

Wang H, Shao X, Li M (2019) A 2917-year tree-ring-based reconstruction of precipitation for the Buerhanbuda Mts., Southeastern Qaidam Basin, China. Dendrochronologia 55:80-92. 
Wells N, Goddard S (2004) A Self-Calibrating Palmer Drought Severity Index. J. Clim. 17:2335-2339.

Yang B, Qin C, Bräuning A, Burchardt I, Liu J (2011) Rainfall history for the Hexi Corridor in the arid northwest China during the past 620 years derived from tree rings. Int J Climatol 31:1166-1176.

Yang B, Qin C, Shi F, Sonechkin DM (2012) Tree ring-based annual streamflow reconstruction for the Heihe River in arid northwestern China from AD 575 and its implications for water resource management. Holocene 22:773-784.

Yang B, Qin C, Wang J, He M, Melvin TM, Osborn TJ, Briffa KR (2014) A 3,500-year tree-ring record of annual precipitation on the northeastern Tibetan Plateau. P Natl Acad Sci USA 111:2903-2908.

Yang B, Wang J, Liu J (2019) A 1556 year-long early summer moisture reconstruction for the Hexi Corridor, Northwestern China. Sci. China Earth Sci 62:https://doi.org/10.1007/s11430-11018-1932711431.

Yin J, Su Y, Fang X (2016a) Climate change and social vicissitudes in China over the past two millennia. Quatern Res 86:133-143.

Yin Z-Y, Shao X, Qin N, Liang E (2008) Reconstruction of a 1436-year soil moisture and vegetation water use history based on tree-ring widths from Qilian junipers in northeastern Qaidam Basin, northwestern China. Int J Climatol 28:37-53.

Yin ZY, Zhu HF, Huang L, Shao XM (2016b) Reconstruction of biological drought conditions during the past 2847 years in an alpine environment of the northeastern Tibetan Plateau, China, and possible linkages to solar forcing. Global Planet Change 143:214-227.

Yoshiaki M (2019) Sixteen Kingdoms of the Five Barbarians: the great migration of nationalities in Chinese history. The Commercial Press, Beijing.

Zhang D, Jim C, Lin C, He Y, Lee F (2005) Climate change, social unrest and dynastic transition in ancient China. Chin Sci Bull 50:137-144.

Zhang DD, Brecke P, Lee HF, He Y-Q, Zhang J (2010) Global climate change, war, and population decline in recent human history. P Natl Acad Sci USA 104:19214-19219.

Zhang H, Zhang Y, Shao X (2015a) Which climatic factors limit radial growth of Qilian juniper at the upper treeline on the northeastern Tibetan Plateau? J Geogr Sci 25:1173-1182.

Zhang J, Gou X, Zhang Y, Lu M, Xu X, Zhang F, Liu W, Gao L (2016) Forward modeling analyses of Qilian Juniper (Sabina przewalskii) growth in response to climate factors in different regions of the Qilian Mountains, northwestern China. Trees 30:175-188. 
Zhang J, Huang X, Wang Z, Yan T, Zhang EY (2018) A late-Holocene pollen record from the western Qilian Mountains and its implications for climate change and human activity along the Silk Road, Northwestern China. Holocene 28:1141-1150.

Zhang P, Cheng H, Edwards RL, Chen F, Wang Y, Yang X, Liu J, Tan M, Wang X, Liu J, An C, Dai Z, Zhou J, Zhang D, Jia J, Jin L, Johnson KR (2008) A test of climate, sun, and culture relationships from an 1810year Chinese cave record. Science 322:940-942.

Zhang Q-B, Evans MN, Lyu L (2015b) Moisture dipole over the Tibetan Plateau during the past five and a half centuries. Nat Commun 6:8062.

Zhang Y, Shao X, Yin Z-Y, Liang E, Tian Q, Xu Y (2011a) Characteristics of extreme droughts inferred from tree-ring data in the Qilian Mountains, 1700-2005. Clim Res 50:141-159.

Zhang Y, Shao X, Yin Z-Y, Tian Q (2013) A dendroclimatic analysis of regional moisture variation in the northeastern Tibetan Plateau during the past 150 years. Trees 27:455-463.

Zhang Y, Shao X, Yin Z-Y, Wang Y (2014) Millennial minimum temperature variations in the Qilian Mountains, China: evidence from tree rings. Clim Past 10:1763-1778.

Zhang Y, Tian Q, Gou X, Chen F, Leavitt SW, Wang Y (2011b) Annual precipitation reconstruction since AD 775 based on tree rings from the Qilian Mountains, northwestern China. Int J Climatol 31:371-381.

Zheng J, Wang W-C, Ge Q, Man Z, Zhang P (2006) Precipitation variability and extreme events in Eastern China during the past 1500 years. Terr Atmos Oceanic Sci 17:579-592.

\section{Tables}

\section{Table 1. Basic information about the YQ chronology.}




\begin{tabular}{|ll|}
\hline Statistics & YQ \\
\hline Time span & $134 \rrbracket 2015$ CE \\
\hline Mean length & 282 \\
\hline Mean sensitivity & 0.385 \\
\hline Common interval analysis (1230-1440 CE) & \\
\hline First-order autocorrelation & 0.195 \\
\hline Average correlation among series & 0.432 \\
\hline Average correlation among trees & 0.425 \\
\hline Average correlation among series in a tree & 0.828 \\
\hline Signal-to-noise ratio & 431.2 \\
\hline Expressed population signal (EPS) & 0.969 \\
\hline Explained variance of the first principal component & $45.3 \%$ \\
\hline EPS >0.85 & $241 \otimes 2015$ CE \\
\hline
\end{tabular}

Table 2. Statistics of the split period calibration/verification.

\begin{tabular}{|c|c|c|c|c|c|c|c|c|c|}
\hline & period & $r$ & $\mathrm{R}^{2}$ & $\mathrm{~F}$ & RE & CE & ST & FST & PMT \\
\hline Calibration & $\begin{array}{l}1952- \\
1983\end{array}$ & 0.76 & 0.58 & 42.08 & & & & & \\
\hline Verification & $\begin{array}{l}1984- \\
2015\end{array}$ & 0.57 & 0.33 & & 0.37 & 0.28 & $22+/ 10-^{*}$ & $24+/ 7-{ }^{* *}$ & 2.85 \\
\hline Calibration & $\begin{array}{l}1984- \\
2015\end{array}$ & 0.57 & 0.33 & 14.72 & & & & & \\
\hline Verification & $\begin{array}{l}1952- \\
1983\end{array}$ & 0.76 & 0.58 & & 0.56 & 0.53 & $20+/ 12-$ & $24+/ 7-^{\star \star *}$ & 2.56 \\
\hline $\begin{array}{l}\text { Full } \\
\text { calibration }\end{array}$ & $\begin{array}{l}1952- \\
2015\end{array}$ & 0.71 & 0.51 & 63.49 & 0.47 & 0.47 & $44+/ 20-^{* * *}$ & $48+/ 15^{* * *}$ & 2.947 \\
\hline
\end{tabular}

$r=$ Pearson correlation coefficient; $R^{2}=$ coefficient of determination; F: statistical significance of the regression models; $\mathrm{RE}=$ reduction of error; $\mathrm{CE}=$ coefficient of efficiency. $\mathrm{RE}$ and/or $\mathrm{CE}>0.0$ shows skill in the model reconstruction. ST: the sign test; FST: the first-difference sign test; PMT: the product-mean test; ${ }^{* \star *}=$ significant at $\mathrm{P}<0.01 ;{ }^{* *}=$ significant at $\mathrm{P}<0.05 ;{ }^{*}=$ significant at $\mathrm{P}<0.1$.

\section{Figures}




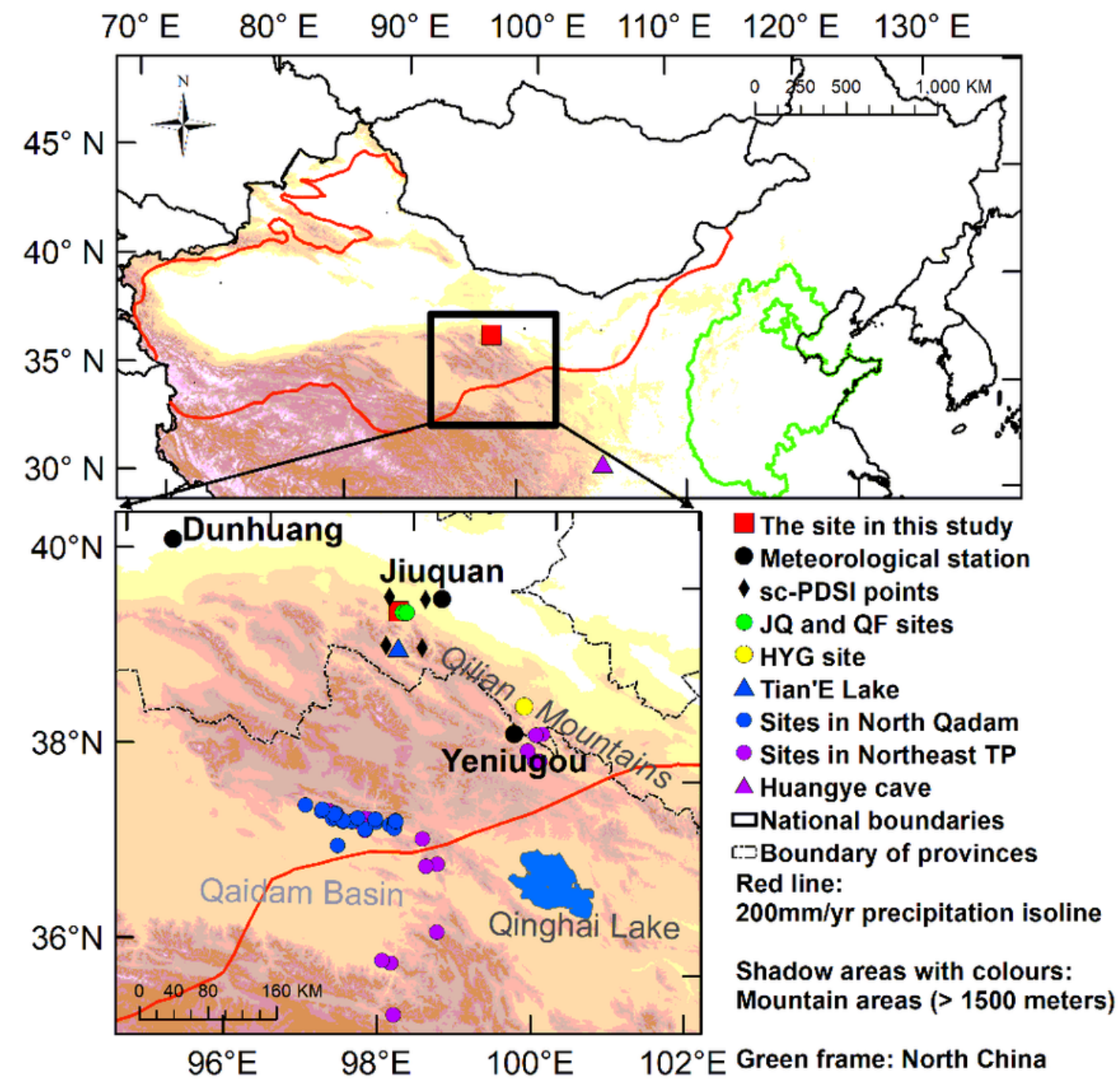

Figure 1

Locations of the tree-ring sampling sites, Jiuquan station, four nearby sc-PDSI grids points, and sites of other climate proxies used in this study(JQ, Gou et al., 2015; QF, Yang et al., 2019; HYG, Zhang et al., 2011; Tian'E lake, Zhang et al., 2018; the Qadam basin, Yin et al., 2016; the northeastern TP, Yang et al., 2014; North China, Zheng et al., 2006; and Huangye Cave, Tan et al., 2010). The 200-mm isohyet of annual mean precipitation (1981-2010) was calculated based on the CRU precipitation dataset (red line).Note: The designations employed and the presentation of the material on this map do not imply the expression of any opinion whatsoever on the part of Research Square concerning the legal status of any country, territory, city or area o bbnhjr of its authorities, or concerning the delimitation of its frontiers or boundaries. This map has been provided by the authors. 


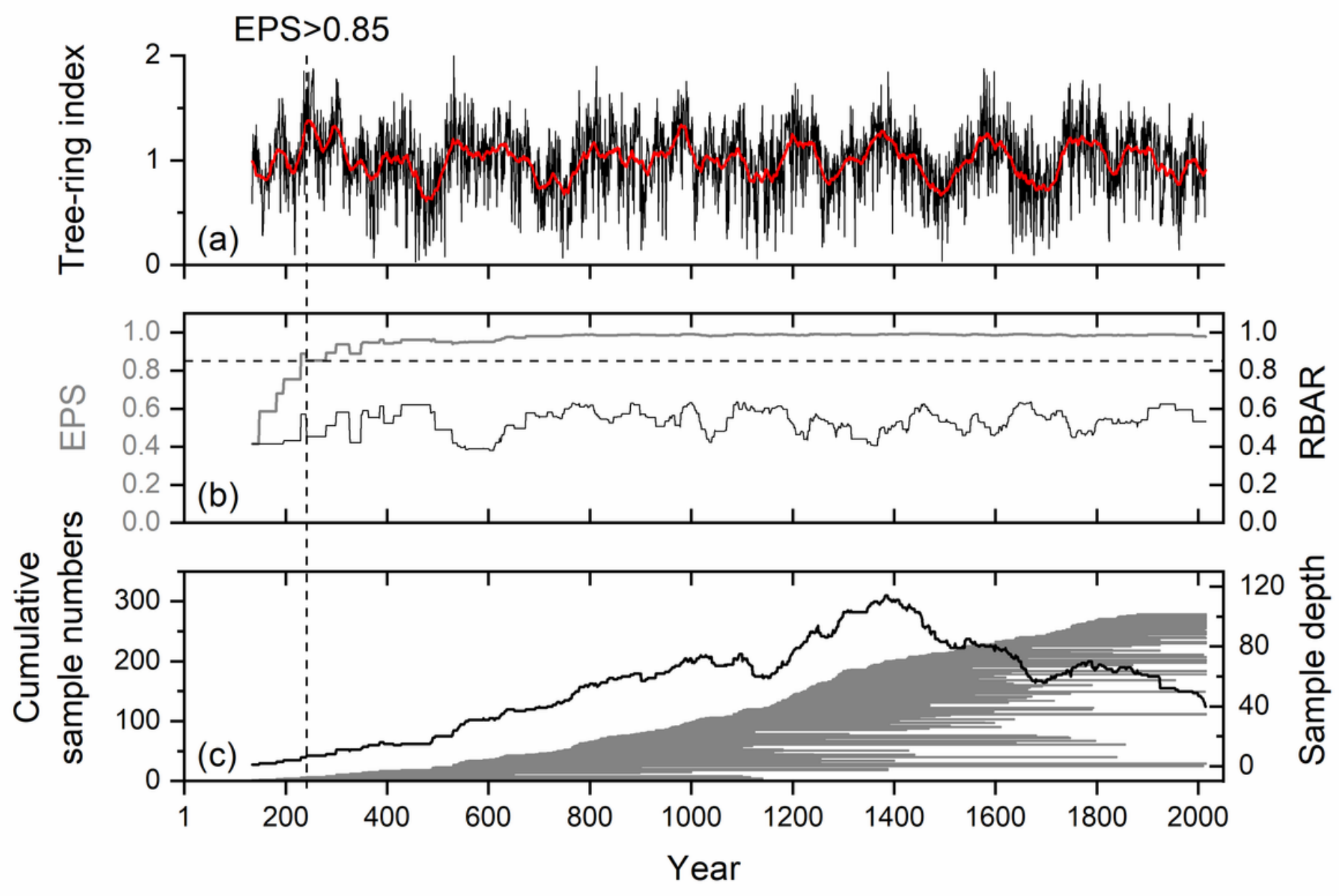

Figure 2

(a) Ring-width chronology (YQ) with a 31-year running mean (red line); (b) EPS and Rbar values; (c) Changing sample size over time (dark line) and cumulative sample numbers. The dotted vertical line denotes the year $241 \mathrm{CE}$, which is when the EPS value exceeds the 0.85 threshold.

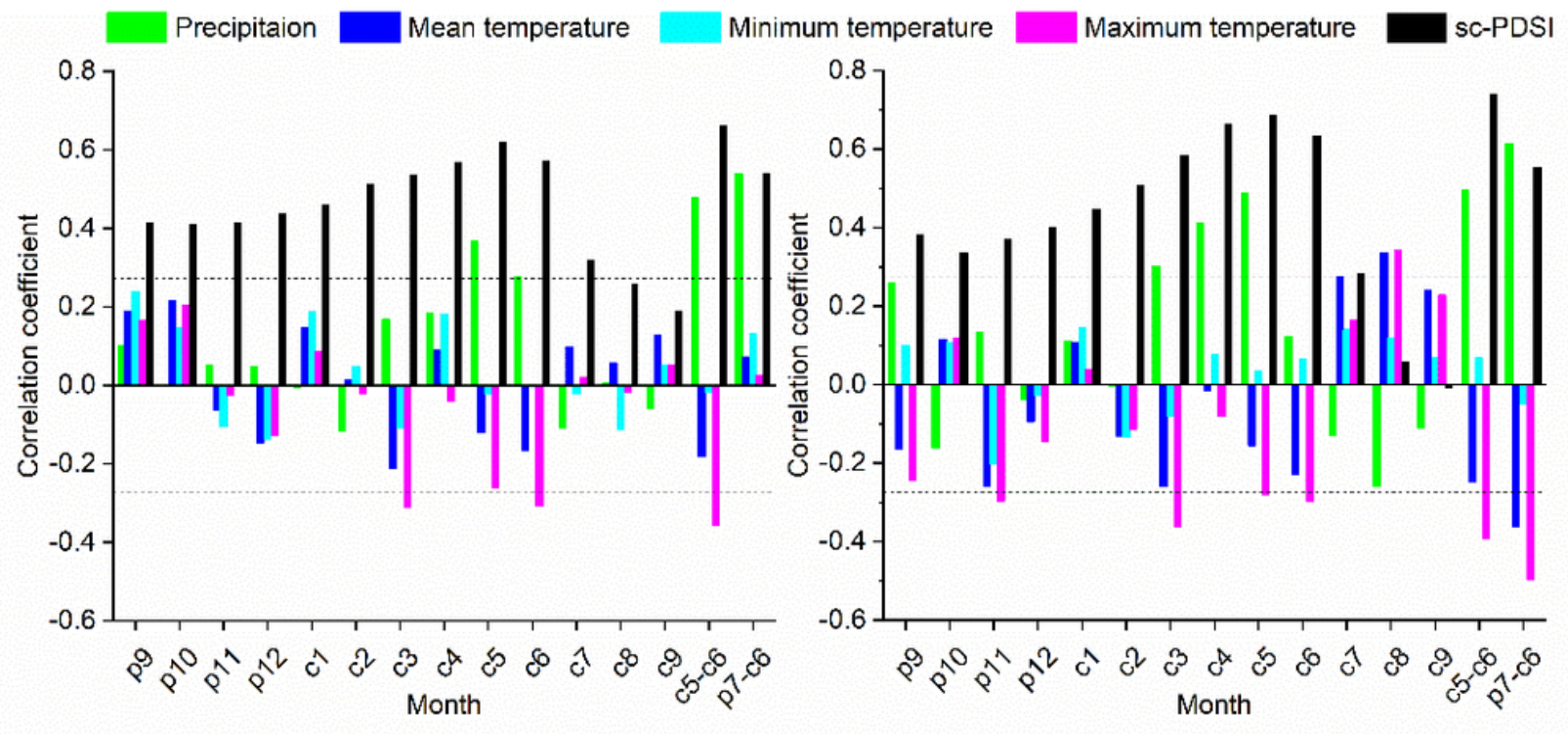


Figure 3

The correlations between the original (right) and first differenced YQ chronology(left) and climate variables from September of the previous year (P9-P12) to August of the current year (C1-C8) during the

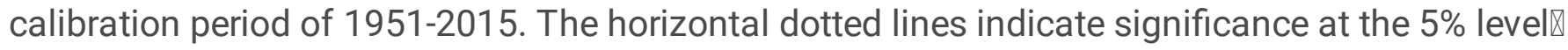
respectively.

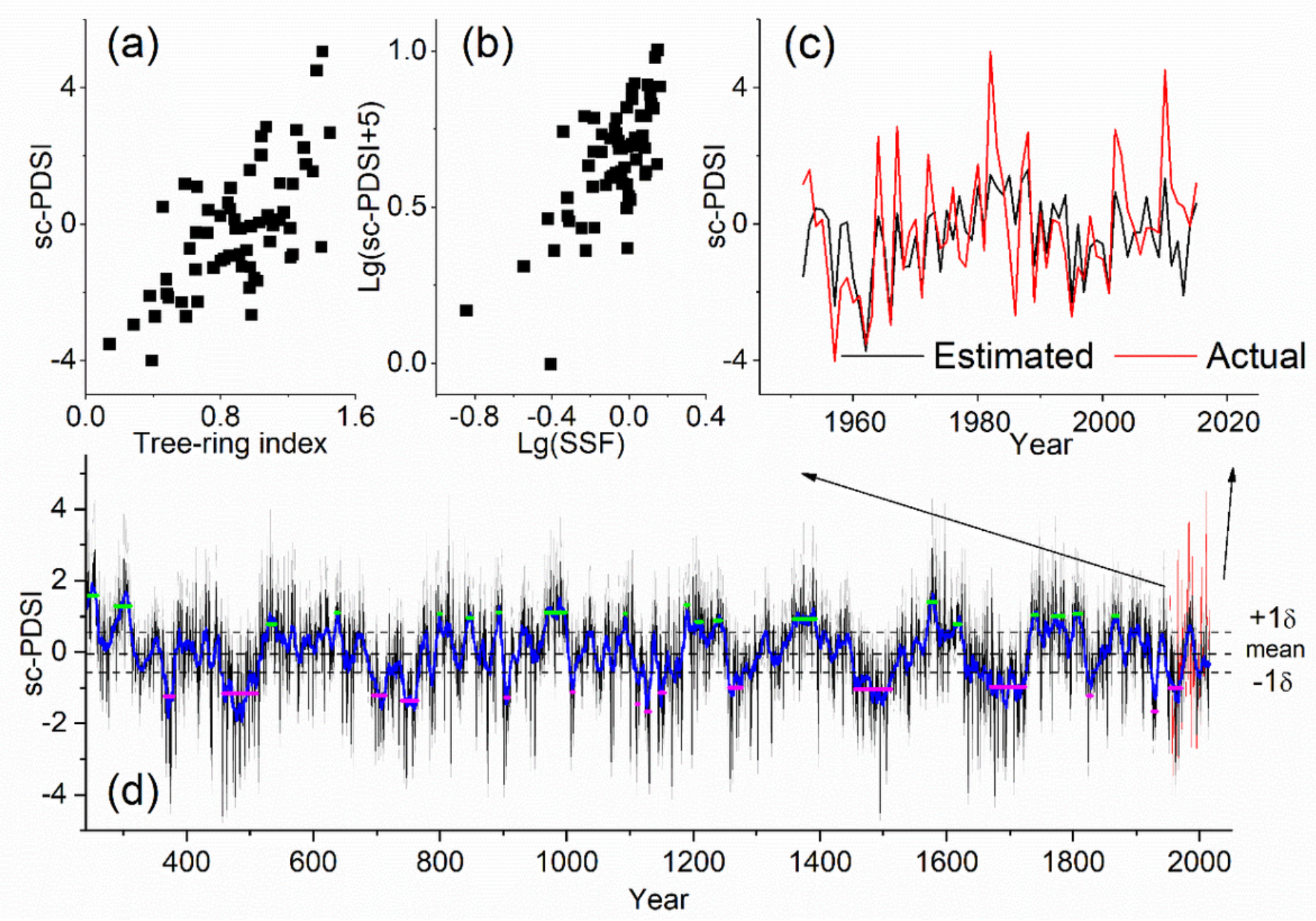

Figure 4

Scatter plots between the (a) original and the (b) logarithmically transformed tree-ring index and sc-PDSl; (c) time series of the actual and estimated Sc-PDSI during the calibration period (1952-2015); and (d) the reconstructed sc-PDSI series (black line) with an 11-year running mean (blue line) and the mean and \pm 1 standard deviation (dotted lines). The thin gray line represents the $95 \%$ confidence interval. Green and pink bars indicate the average and durations of 19 persistent dry and 15 wet events ( $>5$ years). 

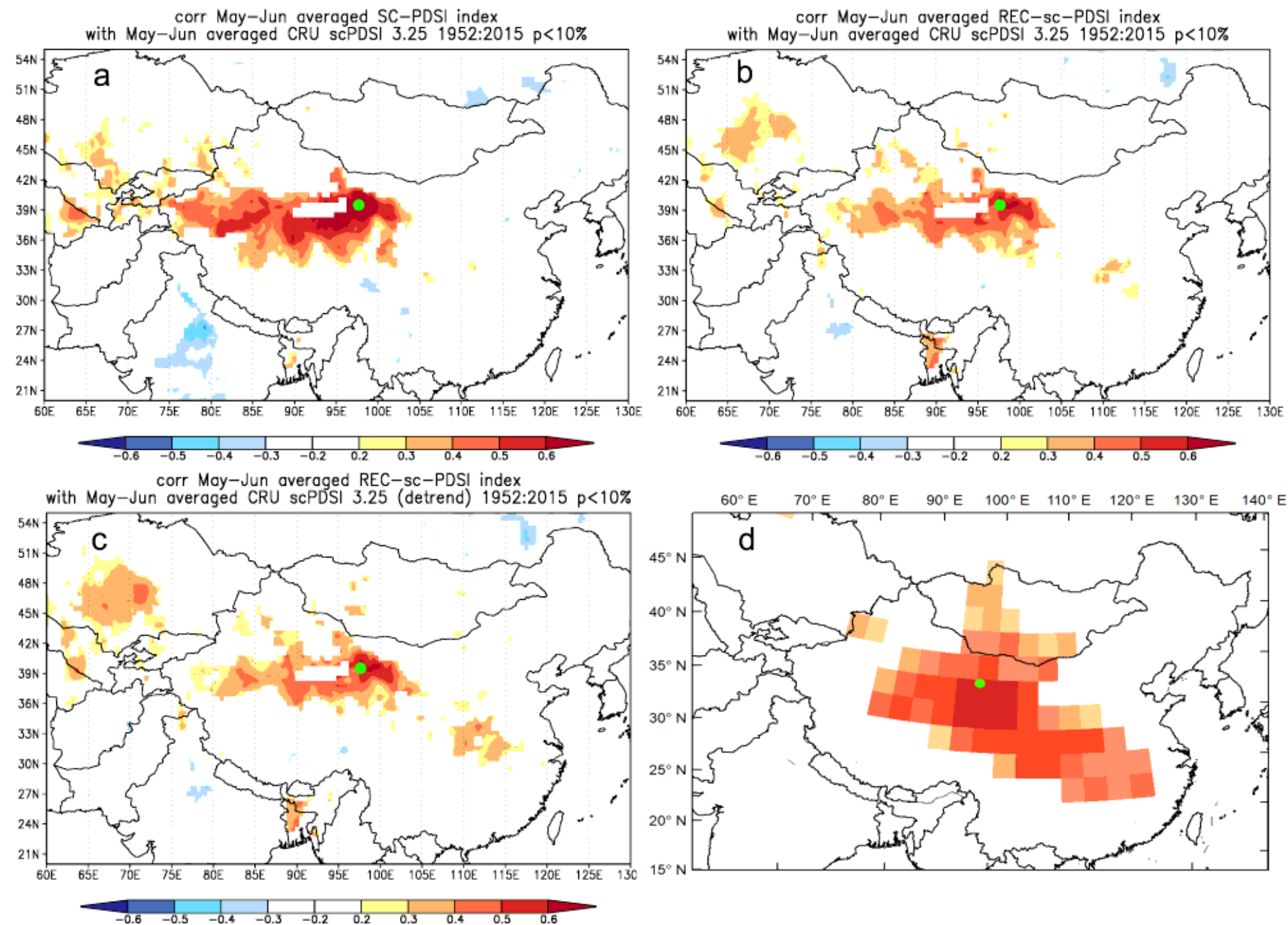

\section{Figure 5}

May-June correlations of the CRU gridded Sc-PDSI with the average sc-PDSI of the four grid points (a) and with the reconstructed Sc-PDSI (b), as well as correlations of detrended reconstructed Sc-PDSI (c) for the period 1952-2015. The empty area in colorful significant area indicated null value in this area. (d) the correlation between the reconstructed sc-PDSI and the gridded PDSI series from the Monsoon Asia Drought Atlas (MADA) (Cook et al., 2010) (1700-2005 CE). The red bars from light to dark indicate the significance of the correlation coefficients ranging from 0.16 to $0.45(p<0.01)$. 


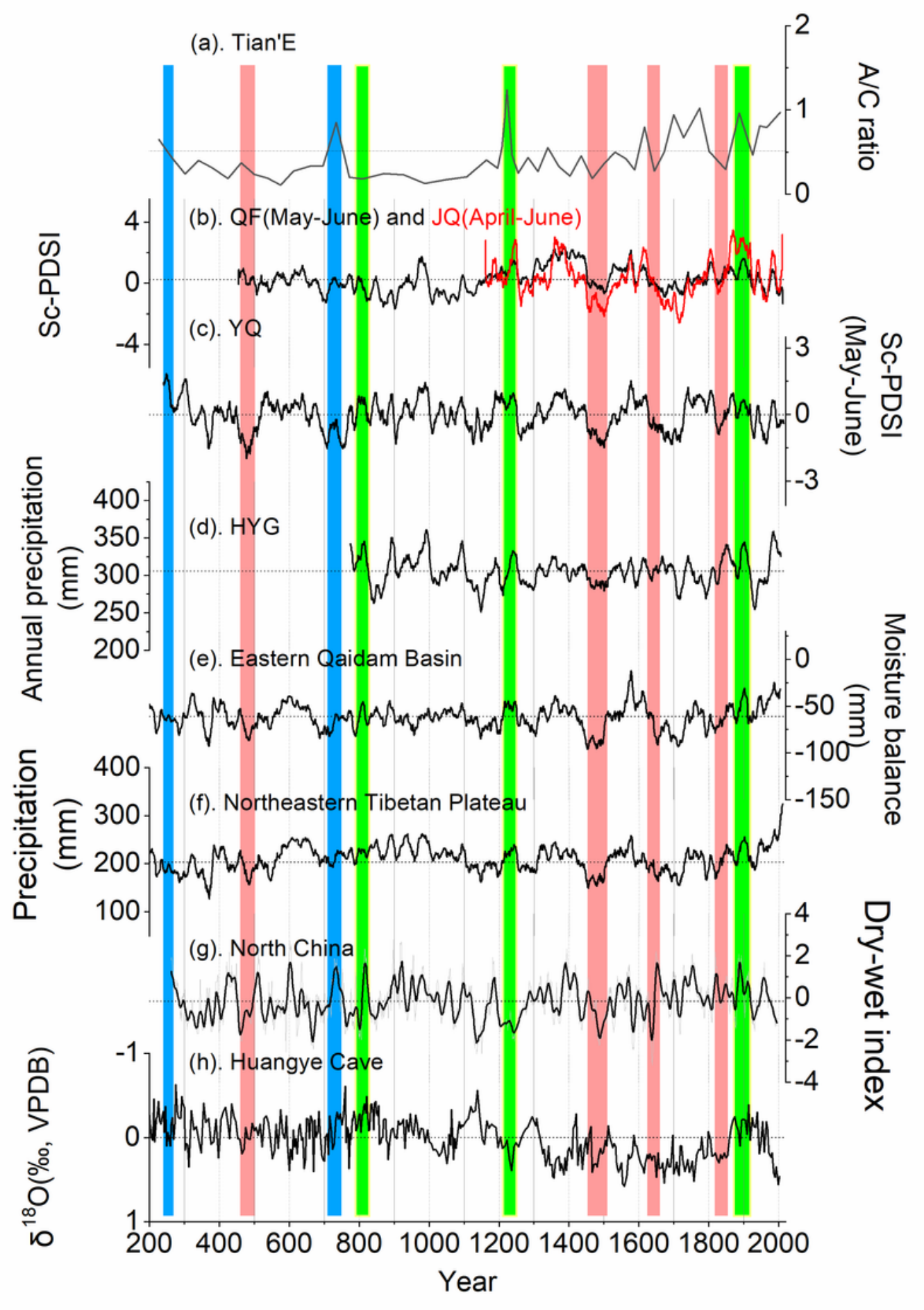

Figure 6

Comparison between the reconstruction presented in this paper (c) and other moisture-related series from the Jiuquan area (a. Zhang et al., 2018; b. Gou et al., 2015(JQ, red line); b. Yang et al., 2019(QF, black line)), the Zhangye area (d. HYG, Zhang et al., 2011), the Qadam basin (e, Yin et al., 2016), the northeastern Tibetan Plateau (f. Yang et al., 2014), north China (g. Zheng et al., 2006), and Huangye Cave in central China (h. Tan et al., 2010). Blue columns indicate the prosperous period of the Silk Road, red 
columns indicate some drought periods in large spatial scale, green columns indicate some pluvial periods in large spatial scale.

(a)

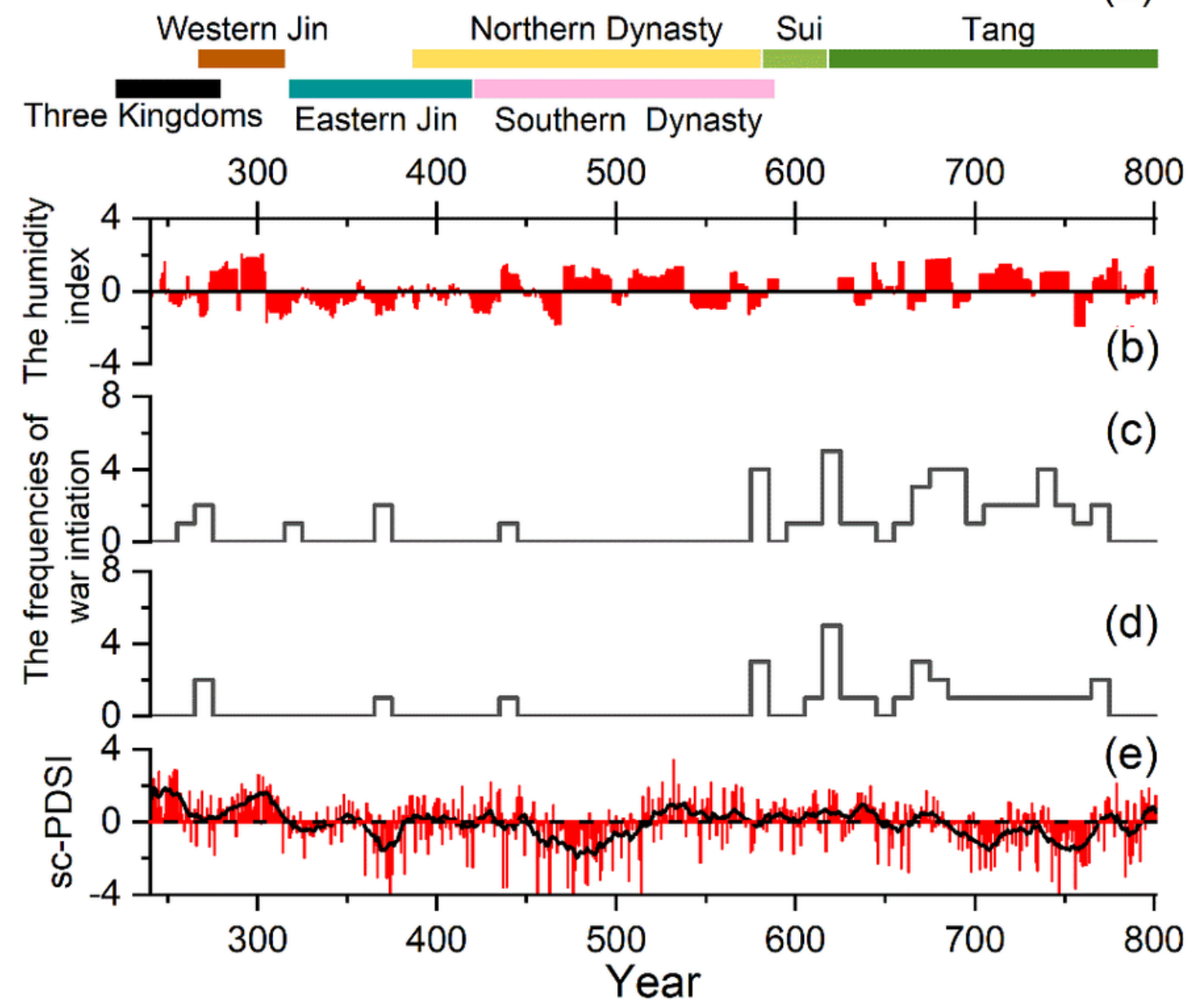

Figure 7

(a) diagrammatic sketch of different dynasties from the 3rd to the 8th century, where individual color bars indicate the time spans of different dynasties; (b) the humidity index of eastern China based on historical documents (Zheng et al., 2006); (c) the frequency of war initiation between nomadic and farming groups in northwestern China (Su et al., 2016); (d) the frequency of wars initiated by nomads in northwestern China (Su et al., 2016); and (e) our reconstructed sc-PDSI series. 